\title{
Phytoecdysteroids: Isolation and Biological Applications
}

\author{
Yahya Al Naggar ${ }^{1, *}$, Mohamed Ghorab ${ }^{2,3}$, Kariman Mohamed ${ }^{4}$ \\ ${ }^{1}$ Department of Zoology, Faculty of Science, Tanta University, Tanta, Egypt \\ ${ }^{2}$ Environmental Toxicology Lab, Central Laboratories Unit, National Institute of Oceanography and Fisheries (NIOF), Alexandria, Egypt \\ ${ }^{3}$ Department of Animal Science, Wildlife Toxicology Laboratory, Michigan State University, East Lansing, MI, USA \\ ${ }^{4}$ Plant Protection Department, Faculty of Agriculture, Suez Canal University, Ismailia, Egypt
}

\section{Email address:}

Yehia.elnagar@science.tanta.edu.eg (Y. Al Naggar)

${ }^{*}$ Corresponding author

\section{To cite this article:}

Yahya Al Naggar, Mohamed Ghorab, Kariman Mohamed. Phytoecdysteroids: Isolation and Biological Applications. American Journal of Life Sciences. Vol. 5, No. 1, 2017, pp. 7-10. doi: 10.11648/j.ajls.20170501.12

Received: December 21, 2016; Accepted: January 23, 2017; Published: February 24, 2017

\begin{abstract}
Phytoecdysteroids are analogues of arthropod steroid hormones found in plants, where they deter predation by non-adapted predators. Their discovery in several plant species displayed a wide array of rather beneficial agricultural impact. An overview is given on both well-known and recently discovered phytoecdyteroids including a sophisticated isolation scheme and notable physiological and pharmacological effects of ecdysteroids on vertebrates.
\end{abstract}

Keywords: Ecdysteroides, Plants, Application, Phytochemistry, Extraction

\section{Introduction}

Phytoecdysteroids are a class of chemicals that plant synthesize for defense against phytophagous (plant eating) insects. These compounds are exact replicas of ecdysteroids, hormones used by the arthropod (insect) and crustacean (crab/lobster) families in the molting process known as ecdysis. Insects that ingest phytoecdysteroids and have not adapted to this defense are subject to serious adverse effects, including reduced weight, molting disruption, and/or mortality (Dinan 2001). Phytoecdysteroids are distributed throughout the plant kingdom, with approximately $6 \%$ of all plants surveyed containing detectable levels of ecdysteroids (Dinan 2001).

\section{Chemistry of Phytoecdysteroids}

Chemically, phytoecdysteroids are classed as triterpenoids, the group of compounds that includes triterpene saponins, phytosterols, and phytoecdysteroids. Ecdysteroids are polar steroids, almost sugar-like in their solubility properties (Gilbert et al. 2002). While mammalian steroid hormones have more variable structures, they universally lack the polyhydroxylated side chain characteristic of ecdysteroids and are therefore more lipophilic (Gilbert et al. 2002). Unlike invertebrates, which are unable to synthesize ecdysteroids and must consume dietary phytosterols that are then converted into ecdysteroids, plants can completely produce ecdysteroids from mevalonic acid and cholesterol (Adler and Grebenok 1995).

The sterol structure is modified to produce ecdysteroids. The trans $\mathrm{A} / \mathrm{B}$ ring juncture in sterols is converted to a cis $\mathrm{A} / \mathrm{B}$ ring juncture in ecdysteroids, and a 7-en-6-one chromophore and a 14 a-hydroxy group are added (Figure. 1) (Davies et al. 1980). Additional hydroxylations at C2, C20, $\mathrm{C} 22$, and $\mathrm{C} 25$ are required to produce the most common phytoecdysteroid, 20-hydroxyecdysone (20HE).

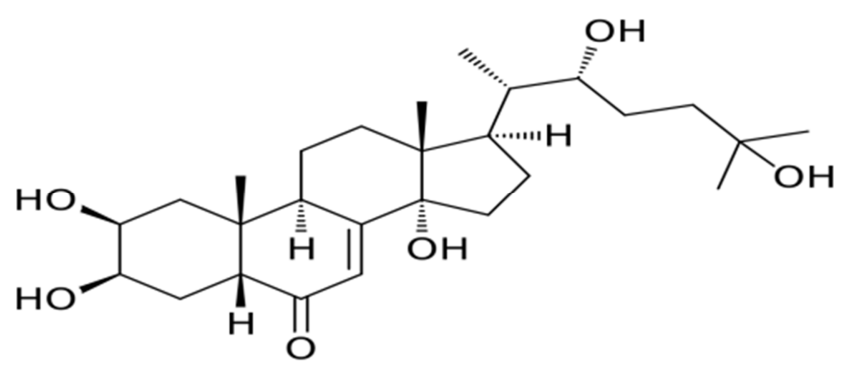

Fig. 1. Chemical structure of the ecdysteroid ecdysone. 


\section{Plant Families with Known Ecdysteroids}

The use of Radio Immuno Absorption (RIA) proved that, most plants contain very low levels, and may retain the biosynthetic capability to produce ecdysteroids in higher levels (Dinan 2001). Approximately 6\% of all plant species synthesize phytoecdysteroids (Dinan 2001). Phytoecdysteroid levels in plants are usually found to be $0.1 \%$ or less of their dry weight and have been isolated from all parts of plants in much higher amounts than those present in arthropods (Dinan 2001). Low concentrations of various phytoecdysteroids deter some insects (2-25 ppm), while other insects are resistant to very high concentrations (400-1000 $\mathrm{ppm})$. The most common phytoecdysteroid found in plants is ecdysone (20Ehydroxyecdysone) (Dinan 2001).

Among plant species highest in phytoecdysteroids is spinach (Spinacia oleracea L., Chenopodiaceae) containing $50 \mathrm{ug} / \mathrm{g}$ fresh weight (Grebenok et al. 1994). Other examples are: ajugasterone in Ajuga L., Lamiaceae and Vitex L., Verbenaceae; leuzeasterone in Leuzea carthamoides (syn. Rhaponticum carthamoides (Willd.) Iljin, Asteraceae); 2 deoxy-20-hydroxyecdysone 3- glucoside and 3-epi-2-deoxy20-hydroxyecdysone in Tinospora cordifolia (Willd.) Miers, Menispermaceae (Song et al. 1991); ecdysterone and inokosterone in Achyranthes bidentata Blume, Amaranthaceae (Gao et al. 2000); polypodine B in Leuzea carthamoides (Pis et al., 1994); and ecdysterone, ajugasterone $\mathrm{C}$, ajugasterone $\mathrm{C}-20,22-$ monoacetonide in Rhaponticum uniflorum (L.) DC., Asteraceae (Zhang et al. 2002).

\section{Isolation of Phytoecdysteroids}

Dried plant parts were extracted at room temperature with a high excess of methanol (e.g., 10-fold). Evaporation, fractional precipitation and solvent-solvent distribution permitted the removal of the abundant amounts of both apolar and polar contamination. A unified scheme has been established for processing the plant extracts to isolate both the known and new ecdysteroids. With this procedure, numerous ecdysteroids have been isolated, and the same scheme is used today to find further new ecdysteroids (Figure 2 ). The first chromatographic step of isolation is lowpressure column chromatography on alumina, which yields 20-hydroxyecdysone in a single-step purification. After crystallization, the purity of 20-hydroxyecdysone is over 99\%. To isolate a minor component (e.g., 2-deoxy- 20hydroxyecdysone, about 30-fold less than 20hydroxyecdysone) requires the double employment of column chromatography, on alumina and/or silica. As certain components are present at a trace level (e.g., 20hydroxyecdysone-22- benzoate, 20-hydroxyecdysone-25glucoside, etc.) their isolation requires the correct combination of various chromatographic procedures (15), such as classic column chromatography on alumina and silica, droplet countercurrent chromatography, HPLC and, sometimes, either preparative TLC or size-exclusion chromatography on an LH-20 Sephadex column. Using this method, over 50 ecdysteroids have been isolated from various plant sources, 32 of which were previously unknown. The key point to note is that consecutive stages in the purification process should be based on different ecdysteroid properties, such as lipophilicity, hydrophilicity, polar/apolar substituents, molecular size, H-bonding, etc. (Báthori \& Kalász 2001).

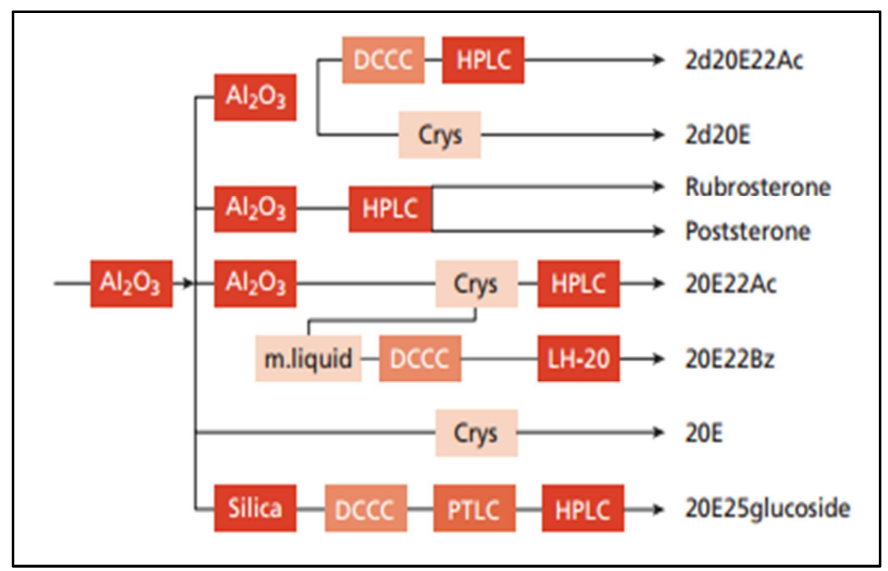

Fig. 2. Unified isolation scheme for phytoecdysteroids. Al2O3 column chromatography on alumina; silica (column chromatography on silica); DCCC droplet countercurrent chromatography; HPLC high performance liquid chromatography; PTLC preparative thin-layer chromatography on silica; LH-20 column chromatography on Sephadex LH-20; Crys crystallization; m.liquid using the mother liquid for further isolation; $20 E$ 20-hydroxyecdysone; 2d 2-deoxy; Ac acetate; Bz benzoate.

\section{Metabolism of Phytoecdysteroids in Vertebrates}

The currently limited understanding of the metabolism of ingested or injected ecdysteroids in mammals is potentially a serious restriction to the use of these compounds as geneswitch elicitors. Almost all indicators are that ecdysteroids are nontoxic to mammals and consumption of ecdysteroidcontaining food (e.g., spinach) is not detrimental. Ecdysteroids appear to be metabolised and excreted relatively rapidly in mice and humans (reviewed in Dinan and Lafont, 2006). However, considering that it is desirable to develop multiple gene switches that can be selectively activated according to ligand specificity, it is necessary to understand the metabolism and pharmacokinetics of ecdysteroids in mammalian systems, so that the correct gene switch is activated over the appropriate time-frame and so that metabolites do not activate inappropriately. A by-product of such studies would be that it should be possible to develop reliable procedures (for an initial step in this direction, using LC-MS, see Le Bizec et al., 2002) to identify whether athletes have consumed significant amounts of ecdysteroids during training, if it should be deemed that such consumption could provide unfair advantage and, thus, be considered "doping" and in need of regulation. In a study on calves (Destrez et al., 2009), it has been shown that orally administered $20 \mathrm{E}$ was very rapidly (within $24 \mathrm{~h}$ ) no longer 
detectable in the urine, but that 2 metabolites, 14-deoxy-20hydroxyecdysone and 20,26-dihydroxyecdysone, could be detected for up to 6 days after the cessation of administration of the parent compound.

\section{Importance of Phytoecdysteroids for Plants and Animals}

Phytoecdysteroids may play a role in plant defense. Production of $20 \mathrm{HE}$ in spinach is elicited by both mechanical wounding and insect feeding. Both exogenous $20 \mathrm{HE}$ and plant produced ecdysteroids produced abnormal molting, immobility, reduced invasion, impaired development, and death in insects (Schmelz et al. 2002). It has been found to protect spinach from plant-parasitic nematodes and may confer a mechanism for nematode resistance (Soriano et al. 2004). Although not conclusive, ecdysteroid's role in plants may be similar to the defensive role of lignins, where production increases in response to pathogens.

The two most common hormones found in insects are the ecdysteroid, 20E hydroxyecdysone (ecdysone) and the sesquiterpene, juvenile hormone. They are usually accompanied by a number of other minor ecdysteroids. The application of very low doses has proven beneficial to improve the synchrony of development and yield of certain commercially important arthropods (Dinan et al., 2009; Lafont and Dinan, 2009). The most extensively studied examples are silk moths (especially Bombyx mori), where protocols have been developed for the preparation of ecdysteroid containing extracts from native plants and application to the food plant (Morus spp.) at particular stages of development, which result in more synchronous cocoon formation and higher yields of silk per cocoon (Changrakala et al., 1998). Benefits may also accrue from the use of low doses of ecdysteroids in apiculture (honey bees; Kholodova, 2001) and aquaculture (shrimps/prawns; Kanazawa et al., 1972).

\section{Pharmaceutical Applications}

The effects of ecdysteroids /phytoecdysteroids are varied and can be divided and briefly summarized as follows.

- Anabolic agents: enhance protein synthesis in a range of mammalian systems. The first reports concerned mouse liver (Otaka et al., 1968).

- Adaptogenic agents: possess adaptogenic, antidepressive, tonic, and roborant properties, i.e., they enhance the ability to cope with stress and enhance resistance to tiredness.

- Anti-diabetic agents: orally-supplied 20E reduces induced hyperglycaemia in rats (Kutepova et al., 2001), stimulates glucose incorporation into glycogen in mouse liver (Yoshida et al., 1971), and enhances glucose utilization by tissues in general (Syrov et al., 1997), by a mechanism that seems to enhance tissue sensitivity to insulin (Kosovsky et al., 1989).

- Hypocholesterolaemic agents: reduce cholesterol levels by reducing biosynthesis, enhancing its catabolism, and promoting conversion into bile acids (Syrov et al., 1986), producing hypocholesterolaemic (Lupien et al., 1969) and antiatherosclerotic (Syrov et al., 1983) effects.

- Wound-healing: promote wound healing in skin with associated stimulation of keratinocyte differentiation. It has been proposed that ecdysteroid application could be useful in the treatment of superficial wounds, burns, and psoriasis (reviewed in Lafont and Dinan, 2008).

- Immunoprotective agents: ecdysteroids have been shown to bring about a number of immunomodulatory effects in mice (Sakhibov et al., 1989), rats (Fomovska et al., 1992), and humans (Trenin and Volodin, 1999) and have anti-inflammatory activity in rodents (Fomovska et al., 1992).

- Toxicity: when ecdysteroids have been tested, they have proven to be non-toxic, with, for example, LD50 values of $6.4 \mathrm{~g} / \mathrm{Kg}$ after intraperitoneal injection and $9 \mathrm{~g} / \mathrm{Kg}$ after oral application of $20 \mathrm{E}$ to mice (Sla'ma and Lafont, 1995). 20E and polB were not embryotoxic when injected into developing chicken eggs (Kosar et al., 1997).

\section{Conclusion}

In view of the above wide-ranging and largely positive effects, it is perhaps not surprising that several food companies are showing interest in adding ecdysteroid-containing plant materials or extracts into food products as a way of enhancing health claims and profit margins. For example, in France at the moment, quinoa (Chenopodium quinoa) is appearing in a very wide range of nutritional products, from pasta, biscuits, and bread to chocolate, drinks, and baby food.

\section{References}

[1] Adler, J. H., \& Grebenok, R. J. (1995). Biosynthesis and distribution of insect-molting hormones in plants - a review. Lipids, 30(3), 257-262.

[2] Changrakala MV, Maribashetty VG, Jyothi HK. 1998. Application of phytoecdysteroids in sericulture. Curr Sci (India) 74:341-346.

[3] Davies, T. G., Lockley, W. J., Boid, R., Rees, H. H., \& Goodwin, T. W. (1980). Mechanism of formation of the A/B cis ring junction of ecdysteroids in Polypodium vulgare. Biochemical Journal, 190(3), 537-544.

[4] Dinan L, Harmatha J, Volodin V, Lafont R. 2009. Phytoecdysteroids: diversity, biosynthesis and distribution. In: Smagghe G, editor. Ecdysone: structures and functions. New York: Springer Science. p 3-45.

[5] Dinan L. 2001, Phytoecdysteroids: biological aspects. Phytochemistry 57:325-339.

[6] Fomovska GN, Berdyshev AG, Kholodova YD. 1992. Immunomodulatory effect of ecdysteroids. Ukrain Biokhim Zh 64:56-61. 
[7] Gao XY, Wang DW, Li FM 2000, Determination of ecdysterone in Achyranthes bidentata Bl. and its activity promoting proliferation of osteoblast-like cells. Yao Xue Xue Bao 35(11):868-870.

[8] Gilbert LI, Rybczynski R, Warren JT 2002, Control and biochemical nature of the ectysteroidogenic pathway. Annual Review of Entomology 47: 883-916

[9] Grebenok, RJ et al 1994, Biosynthesis of ecdysone and ecdysone phosphates in spinach. Phytochemistry 36:13991408.

[10] Kamba M et al 1994, 22-deoxy-20-hydroxyecdysone and its phosphoric ester from ovaries of the silkworm, Bombyx mori. Insect Biochem Molec Biol 24:395-402.

[11] Kanazawa A, Tanaka N, Kashiwada K. 1972. Nutritional requirements of prawns-IV. The dietary effect of ecdysones. Bull Jap Soc Sci Fish 38:1067-1071.

[12] Kholodova YD. 2001. Phytoecdysteroids: biological effects, application in agriculture and complementary medicine. Ukr Biokhim Zh 73:21-29.

[13] Kosar K, Opletal L, Vokac K, Harmatha J, Sovova M, Cerovsky J, Kratky F, Dvorak J. 1997. Embryotoxicity of 20hydroxyecdysone and polypodine $\mathrm{B}$ from Leuzea carthamoides DC. Pharmazie 52:406-407.

[14] Kosovsky MI, Syrov VN, Mirakhmedov MM, Katkova SP, Khushbaktova ZA. 1989. The effect of nerobol and ecdysterone on processes related to insulin regulatory function in normal and in experimental insulin resistance. Probl Endokrinol 35:77-81.

[15] Kutepova TA, Syrov VN, Khushbaktova ZA, Saatov Z. 2001. Hypoglycemic activity of the total ecdysteroid extract from Ajuga turkestanica. Pharm Chem J 35:608-609.

[16] Lafont R, Dinan L. 2009. Innovative and future applications for ecdysteroids. In: Smagghe G, editor. Ecdysone: structures and functions. New York: Springer Science. p 551-578.

[17] Lupien PJ, Hinse C, Chaudhary KD. 1969. Ecdysone as a hypocholesterolemic agent. Arch Int Physiol Biochim 77:206212.

[18] Otaka T, Uchiyama M, Okui S, Takemoto T, Hikino H, Ogawa S, Nishimoto N. 1968. Stimulatory effect of insect metamorphosing steroids from Achyranthes and Cyathula on protein synthesis in mouse liver. Chem Pharm Bull 16:24262429.

[19] Sakhibov AD, Syrov VN, Usmanova AS, Abakumova OY. 1989. Experimental analysis of the immunotropic action of phytoecdysteroids. Dok Akad Nauk Uzbek SSR (8) 55-57.

[20] Schmelz, E. A., Grebenok, R. J., Ohnmeiss, T. E., \& Bowers, W. S. (2002). Interactions between Spinacia oleracea and Bradysia impatiens: a role for phytoecdysteroids. Archives of insect biochemistry and physiology, 51(4), 204-221.

[21] Sla'ma K, Lafont R. 1995. Insect hormones: ecdysteroids: their presence and actions in vertebrates. Eur $\mathrm{J}$ Entomol 92:355-377.

[22] Song CQ \& RS Xu 1991, Phytoecdysones from the roots of Tinospora capillipes. Chinese Chemical Letters 2(1):13-14.

[23] Soriano, I. R., Riley, I. T., Potter, M. J., \& Bowers, W. S. (2004). Phytoecdysteroids: a novel defense against plantparasitic nematodes. Journal of chemical ecology, 30(10), 1885-1899.

[24] Syrov VN, Khushbaktova ZA, Abzalova MK, Sultanov MB. 1983. On the hypolipidemic and antiatherosclerotic action of phytoecdysteroids. Dok Akad Nauk Uzbek SSR (9) 44-45.

[25] Syrov VN, Khushbaktova ZA, Tashmukhamedova MA. 1997. Hypoglycemic action of phytoecdysteroids and some aspects of its mechanism of realization in experimental animals. Dok Akad Nauk Resp Uzbek (4) 46-49.

[26] Syrov VN, Nabiev AN, Sultanov MB. 1986b. The effect of phytoecdysteroids on the bile secretion function of the liver in normal rat and animals with experimental hepatitis. Farmakol Toksikol 49:100-103.

[27] Trenin DS, Volodin VV. 1999. 20-Hydroxyecdysone as a human lymphocyte and neutrophil modulator: in vitro evaluation. Arch Insect Biochem Physiol 41:156-161.

[28] Yoshida T, Otaka T, Uchiyama M, Ogawa S. 1971. Effect of ecdysterone on hyperglycemia in experimental animals. Biochem Pharmacol 20:3263-3268.

[29] Zhang YH, Cheng JK, Yang L et al 2002, Triterpenoids from Rhaponticum uniflorum. Journal of the Chinese Chemical Society 49:117-124. 